\title{
Level of arterial ligation in total mesorectal excision (TME): an anatomical study
}

\author{
Mark Buunen • Marilyne M. Lange • Max Ditzel • \\ Geert-Jan Kleinrensink • Cees J. H. van de Velde • \\ Johan F. Lange
}

Accepted: 23 June 2009 / Published online: 16 July 2009

(C) The Author(s) 2009. This article is published with open access at Springerlink.com

\begin{abstract}
Introduction High-tie ligation is a common practice in rectal cancer surgery. However, it compromises perfusion of the proximal limb of the anastomosis. This anatomical study was designed to assess the value of low-tie ligation in order to obtain a tension-free anastomosis.

Materials and methods Consecutive high- and low-tie resections were performed on 15 formalin-fixed specimens, with or without splenic flexure mobilization. If the proximal colon limb could reach the superior aspect of the symphysis pubis with more than $3 \mathrm{~cm}$, the limb would be long enough for a tension-free colorectal anastomosis.

Results In $80 \%$ of cases, it was not necessary to perform high-tie ligation as sufficient length was gained with low-tie ligation. The descending branch of the left colic artery was the limiting factor in the other $20 \%$ of cases. Resecting half the sigmoid resulted in four times as many tension-free anastomoses after low-tie resection.

Conclusion In the majority of cases, it was not necessary to perform high-tie ligation in order to create a tension-free anastomosis. Low-tie ligation was applicable in $80 \%$ of
\end{abstract}

M. Buunen $(\square) \cdot$ M. Ditzel $\cdot$ J. F. Lange

Department of Surgery, Erasmus Medical Center,

Room Z-835, Dr. Molewaterplein 40,

3015 GD Rotterdam, The Netherlands

e-mail: m.buunen@erasmusmc.nl

M. M. Lange - C. J. H. van de Velde

Department of Surgery, Leiden University Medical Center,

Leiden, The Netherlands

G.-J. Kleinrensink

Department of Neurosciences-Anatomy,

Lowlands Institute of Surgical and Applied Anatomy (LISA),

Erasmus Medical Center,

Rotterdam, The Netherlands cases and might prevent anastomotic leakage due to insufficient blood supply of the proximal colon limb.

Keywords Vascular anatomy · Anastomosis · Inferior mesenteric artery $\cdot$ Rectal cancer

\section{Introduction}

Anastomotic leakage is a severe complication after rectal cancer surgery. Significant morbidity and mortality are reported and numerous risk factors have been identified [1, 2]. One of the causes of anastomotic leakage is represented by too much tension on the anastomosis due to a short proximal colon limb leading to decreased perfusion. Many surgeons prefer to perform high-tie ligation, i.e., ligation of the inferior mesenteric artery because of oncological reasons $[3,4]$. As a result, the left colic artery must be sacrificed making the blood supply to the anastomosis completely dependent on an intact marginal artery of Drummond [5].

As no consensus exists on high-tie ligation for oncological reasons, we investigated if a tension-free anastomosis at the level of the pelvic floor as in total mesorectal excision (TME) for rectal carcinoma can be made by performing low-tie ligation (i.e., ligation of the superior rectal artery). As some surgeons excise the entire sigmoid together with the rectum with respect to a better quality of the proximal colon limb, we both determined the possibility of low-tie ligation after excision of half and the entire sigmoid.

\section{Materials and methods}

A total of 15 human formalin-fixed specimens, seven males and eight females, aged 60 to 98 years (median age, 
81 years) were the subject of this study. Any specimen with previous abdominal or vascular diseases was excluded. No ethical committee approval was necessary for this study.

Operating procedure

The ventral abdominal wall was opened through a midline incision, and the small intestine was removed en bloc in order to get a clear view of the dorsal abdominal wall. The peritoneum was incised at the level of bifurcation of the aorta. The inferior mesenteric artery (IMA) was identified. All vessels branching off of IMA were identified by fine anatomical dissection to the point of the smallest visible branches. The IMA, left colic artery (LCA), descending branch of the left colic artery, sigmoid arteries, and the superior rectal artery (SRA) were all marked by a unique colored thread.

The next step was the mobilization of the descending colon, sigmoid, and rectum. The origin and midsection of the sigmoid were marked; a marker was tied around the sigmoid at the level of anterior superior iliac spine marking the beginning of the sigmoid, and another marker was placed halfway of the sigmoid. Finally, the rectosigmoid junction was transected to completely mobilize the sigmoid (Figs. 1 and 2).

The premise of this study was that if the proximal colon limb overreached the superior aspect of the symphysis pubis with at least $3 \mathrm{~cm}$, the limb would be long enough to reach the pelvic floor for a tension-free colorectal anastomosis.

Measurements were performed in two stages, with and without splenic flexure mobilization. Both stages consisted of measurements of the distance of the cranial and caudal

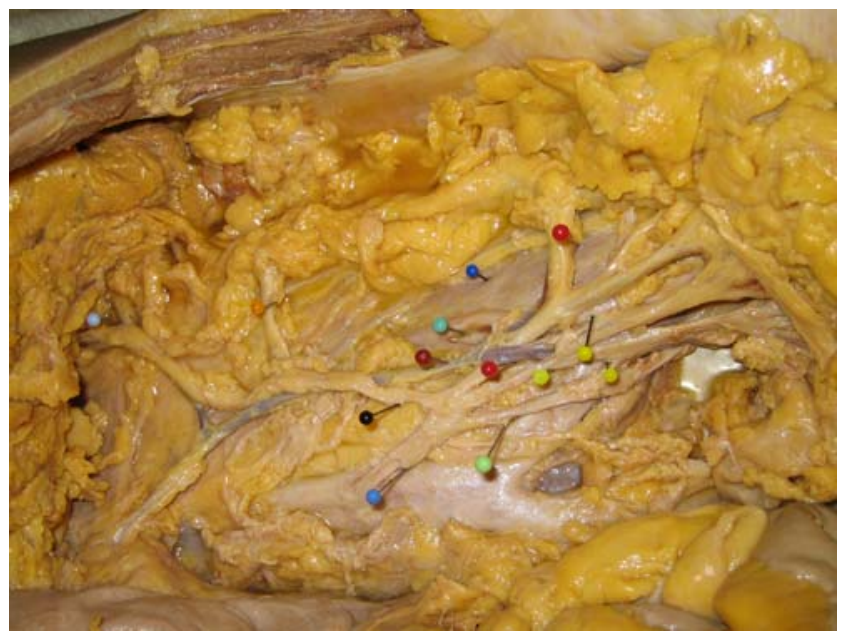

Fig. 1 Setup (black = ascending branch of left colic artery (orange and bright blue are branches anastomosing with the middle colic artery), light blue $=$ inferior mesenteric artery, green $=$ upper rectal artery, bright red $=$ descending branch of left colic artery, yellow $=$ sigmoid arteries, dark red $=$ inferior mesenteric vein, turquoise $=$ urether)

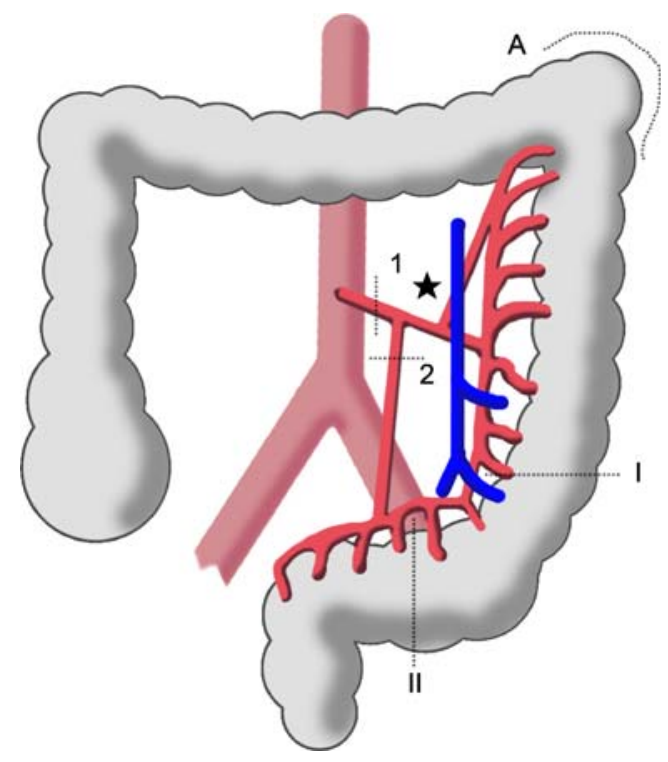

Fig. 2 Performed procedures. 1 High-tie ligation (transection of the inferior mesenteric artery), 2 low-tie ligation (transection of the superior rectal artery), star left colic artery with descending and ascending branch, $I$ complete sigmoid resection, II partial sigmoid resection, $A$ splenic flexure mobilization

cord around the sigmoid to the superior aspect of the symphysis pubis, representing a complete and partial sigmoid resection. All measurements were then performed after low-tie and high-tie transections of vessels. High tie was defined as transection of IMA at $1 \mathrm{~cm}$ from the aorta and IMV at the same level. Low tie was defined as transection of SRA at $1 \mathrm{~cm}$ from the origin of the left colic artery and IMV at the same level as in high-tie transection.

\section{Results}

The IMA and IMV, together with all branches, were easily identified in all cases by fine anatomical dissection. In all cases after resecting half of the sigmoid, a tension-free anastomosis could be created. In five cadavers (33\%), lowtie ligation was sufficient without mobilizing the splenic flexure. Additional splenic flexure mobilization raised success percentages to $80 \%$ (12 cadavers). After high-tie ligation, these percentages were $26 \%$ and $100 \%$, respectively.

Table 1 Number (and percentage) of cases with sufficient length for a tension-free anastomosis

\begin{tabular}{llllll}
\hline & \multicolumn{2}{l}{ Half sigmoid } & & \multicolumn{2}{l}{ Whole sigmoid } \\
\cline { 2 - 3 } \cline { 5 - 6 } & $\begin{array}{l}\text { No } \\
\text { splenic }\end{array}$ & $\begin{array}{l}\text { Splenic } \\
\text { mobilization }\end{array}$ & & $\begin{array}{l}\text { No } \\
\text { splenic }\end{array}$ & $\begin{array}{l}\text { Splenic } \\
\text { mobilization }\end{array}$ \\
\hline High tie & $4(26)$ & $15(100)$ & & 0 & $11(73)$ \\
Low tie & $5(33)$ & $12(80)$ & & 0 & $3(20)$ \\
\hline
\end{tabular}


Table 2 Average length of supplying loop below the superior edge of the pubic bone (in centimeter) after high- or low-tie division, with or without splenic flexure mobilization depending on resection type

\begin{tabular}{llllll}
\hline & \multicolumn{2}{l}{ Half sigmoid } & & \multicolumn{2}{l}{ Whole sigmoid } \\
\cline { 2 - 3 } \cline { 5 - 6 } & $\begin{array}{l}\text { No } \\
\text { splenic }\end{array}$ & $\begin{array}{l}\text { Splenic } \\
\text { mobilization }\end{array}$ & & $\begin{array}{l}\text { No } \\
\text { splenic }\end{array}$ & $\begin{array}{l}\text { Splenic } \\
\text { mobilization }\end{array}$ \\
\hline High tie & 2.1 & 16.3 & & -9.3 & 6.5 \\
Low tie & 1.9 & 9.1 & & -9.9 & -0.2 \\
\hline
\end{tabular}

Resecting the entire sigmoid made splenic flexure mobilization a necessity in all cases regardless of the level of arterial ligation. After mobilizing the splenic flexure, a tension-free anastomosis after resecting the entire sigmoid was obtained in three cases $(20 \%)$ with low-tie ligation and 11 cases $(73 \%)$ with high-tie ligation (see Table 1).

In two cases, the descending branch of the left colic artery was a limiting factor in bringing down the proximal part of the sigmoid into the pelvic cavity when LCA was preserved. In these cases, the descending branch was sacrificed while leaving LCA and its ascending branch intact.

Mobilizing the splenic flexure created on average enough length for the proximal colon limb to reach the pelvic floor. Except when the entire sigmoid was resected

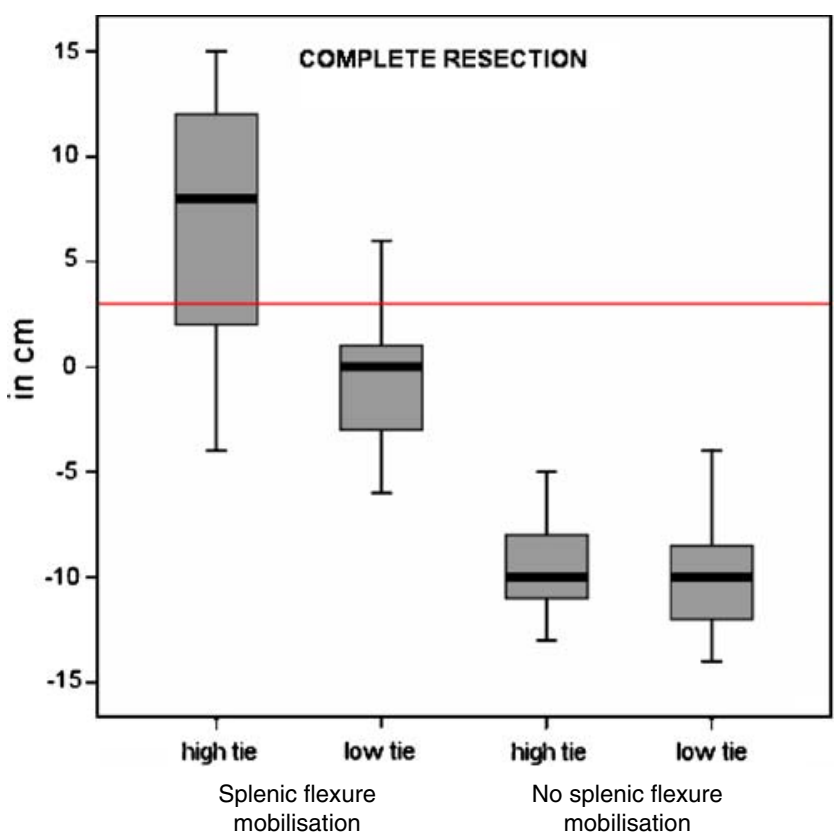

Fig. 3 Boxplot of the length of descending loop (in centimeter) to the superior aspect of the symphysis pubis after complete sigmoid resection, high-tie versus low-tie ligation (negative values indicate shortage of descending loop to the superior aspect of the symphisis pubis, positive values indicate surplus length of descending loop to the superior aspect of the symphisis pubis). The red line indicates the $3-\mathrm{cm}$ limit of overreach by the descending loop and low-tie ligation was performed, the proximal colon limb was on average $3.2 \mathrm{~cm}$ too short (Table 2). A graphical representation of the results is shown in Figs. 3 and 4.

\section{Discussion}

Anastomotic leakage is a frequently reported complication after rectal cancer surgery (5-26\%) and is associated with high morbidity and mortality rates [2, 6, 7]. The importance of surgical detail such as the construction of a tension-free anastomosis with good blood supply is fundamental $[5,8]$. There are several surgical techniques to create sufficient length of the proximal anastomotic limb. The first consideration would be to perform a partial rather than a complete sigmoid resection. As a principle, this would be a problem in case of a narrow thick-walled sigmoid due to diverticulosis. The second option is represented by the mobilization of the splenic flexure. However, mobilizing the splenic flexure results in prolonged operating time and risk of iatrogenic splenic injury $[9,10]$. The third option is to perform high-tie instead of low-tie ligation. Ligation of IMA, flush to its origin at the aorta, has been practiced for many years, assuming a better oncological clearance [11]. However, clinical studies concerning survival after high-tie and low-tie ligation have been published without any

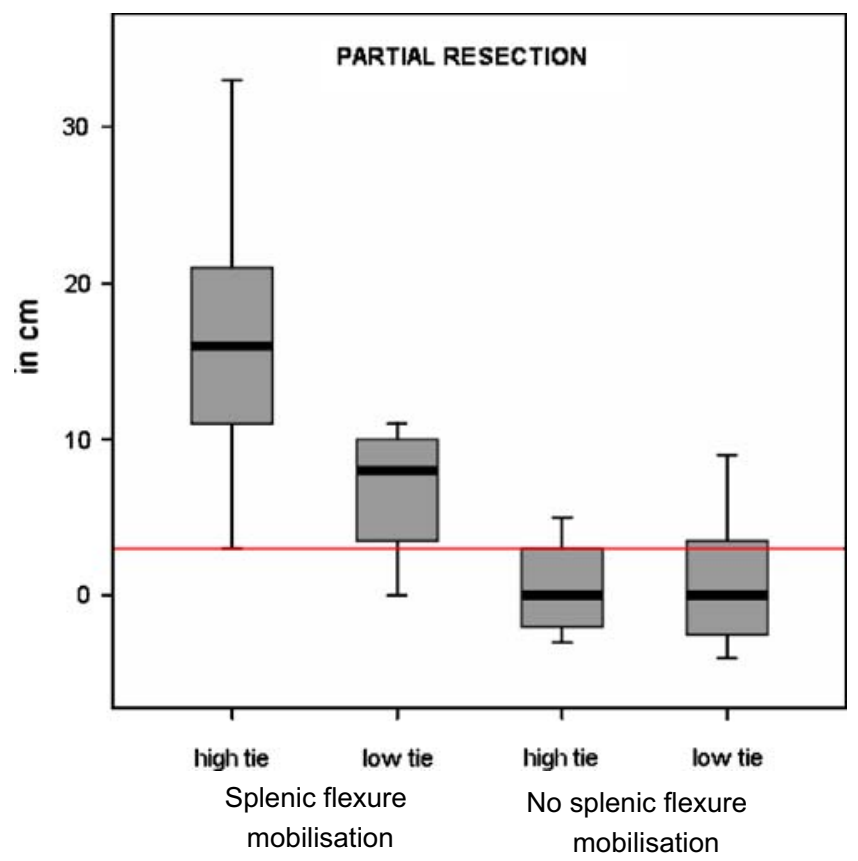

Fig. 4 Boxplot of the length of descending loop (in centimeter) to the superior aspect of the symphysis pubis after partial resection of the sigmoid, high-tie versus low-tie ligation (negative values indicate shortage of descending loop to the superior aspect of the symphisis pubis, positive values indicate surplus length of descending loop to the superior aspect of the symphisis pubis). The red line indicates the $3-\mathrm{cm}$ limit of overreach by the descending loop 
differences, justifying the use of low-tie ligation $[3,4,12]$. Moreover, damage to the inferior mesenteric plexus which forms a dense network around IMA is unavoidable in most cases with subsequent results on sympathetic nerve function (i.e., retrograde ejaculation and urinary incontinence) [13]. Furthermore, high-tie ligation results in a decreased perfusion of the proximal limb of the anastomosis as it is solely dependent from the medial colic artery [14, 15]. Low-tie ligation might improve oxygenation of the anastomosis and might decrease the number of local recurrence rates associated with anastomotic leakage [16].

The necessity of sacrificing LCA in order to obtain sufficient length of the proximal colon limb to create a tension-free anastomosis after (ultra-) low anterior resection has not been proven.

Our results show that in the majority of cases low-tie ligation is sufficient for restoration of bowel continuity. Resecting half the sigmoid and mobilizing the splenic flexure may leave LCA intact. In $80 \%$ of cases, this would be sufficient to create a tension-free anastomosis. Although there is a $100 \%$ success rate by performing high-tie ligation, it is desirable to avoid mesenteric plexus injury, and the anastomosis will not be solely dependent on Drummonds' marginal artery. In the other $20 \%$ of cases, during operation the surgeon is obliged to go back to the arterial blood supply of the sigmoid and still has to ligate IMA that may prolong operating time. However, the risk of a severe complication of anastomotic leakage outweighs prolonged operating time.

In addition, our data show a requirement for splenic flexure mobilization. The best moment to decide whether or not splenic flexure mobilization is necessary would be after resecting the rectum and at the time of anastomosis creation. The data presented here indicate that splenic flexure mobilization is unnecessary in $26 \%$ to $33 \%$ of cases, which could result in iatrogenic splenic injury. However, when the surgeon decides to resect the whole sigmoid, splenic mobilization is indicated in all cases.

A limitation of this study is the use of embalmed specimens. Formalin fixation causes a soft tissue contraction, which results in shortening of the gastrointestinal tract. However, as body length will not be influenced, the relative endpoints are still answered. In vivo, after either a high-tie or low-tie procedure, the gastrointestinal tract is more flexible and more likely to increase in length. This supports the concept of a low-tie transection. As in our study, when low-tie transection does not provide sufficient lengthening of the proximal limb, in vivo, it might.

In conclusion, in most cases, low-tie ligation of SRA can be safely performed for colorectal anastomosis in TME for rectal cancer. Sometimes, it is necessary to sacrifice the descending branch of LCA. Only in case of a diseased sigmoid when complete sigmoid resection is necessary, high-tie strategy is indicated.
Acknowledgement We would like to thank Ms L.S.G.L. Wauben for her contribution to Fig. 2.

Open Access This article is distributed under the terms of the Creative Commons Attribution Noncommercial License which permits any noncommercial use, distribution, and reproduction in any medium, provided the original author(s) and source are credited.

\section{References}

1. Soeters PB, de Zoete JP, Dejong CH, Williams NS, Baeten CG (2002) Colorectal surgery and anastomotic leakage. Dig Surg 19 (2):150-155

2. Peeters KC, Tollenaar RA, Marijnen CA et al (2005) Risk factors for anastomotic failure after total mesorectal excision of rectal cancer. Br J Surg 92(2):211-216

3. Pezim ME, Nicholls RJ (1984) Survival after high or low ligation of the inferior mesenteric artery during curative surgery for rectal cancer. Ann Surg 200(6):729-733

4. Surtees P, Ritchie JK, Phillips RK (1990) High versus low ligation of the inferior mesenteric artery in rectal cancer. Br J Surg 77 (6):618-621

5. Nano M, Dal Corso H, Ferronato M, Solej M, Hornung JP, Dei Poli M (2004) Ligation of the inferior mesenteric artery in the surgery of rectal cancer: anatomical considerations. Dig Surg 21 (2):123-126 discussion 6-7

6. Guenaga KF, Matos D, Castro AA, Atallah AN, Wille-Jorgensen P. Mechanical bowel preparation for elective colorectal surgery. Cochrane Database Syst Rev 2003(2):CD001544.

7. Vlot EA, Zeebregts CJ, Gerritsen JJ, Mulder HJ, Mastboom WJ, Klaase JM (2005) Anterior resection of rectal cancer without bowel preparation and diverting stoma. Surg Today 35(8):629-633

8. Bruch HP, Schwandner O, Schiedeck TH, Roblick UJ (1999) Actual standards and controversies on operative technique and lymph-node dissection in colorectal cancer. Langenbecks Arch Surg 384(2):167-175

9. Brennan DJ, Moynagh M, Brannigan AE, Gleeson F, Rowland M, O'Connell PR (2007) Routine mobilization of the splenic flexure is not necessary during anterior resection for rectal cancer. Dis Colon Rectum 50(3):302-307 discussion 7

10. Ignjatovic D, Djuric B, Zivanovic V (2001) Is splenic lobe/ segment dearterialization feasible for inferior pole trauma during left hemicolectomy? Tech Coloproctol 5(1):23-25

11. Lange M, Buunen M, van de Velde C, Lange J (2008) Central arterial ligation in rectal cancer surgery: low-tie preferred over high-tie. A review. Dis Colon Rectum 51(7):1139-1145

12. Uehara K, Yamamoto S, Fujita S, Akasu T, Moriya Y (2007) Impact of upward lymph node dissection on survival rates in advanced lower rectal carcinoma. Dig Surg 24(5):375-381

13. Hoer J, Roegels A, Prescher A, Klosterhalfen B, Tons C, Schumpelick V (2000) Preserving autonomic nerves in rectal surgery. Results of surgical preparation on human cadavers with fixed pelvic sections. Chirurg 71(10):1222-1229

14. Dworkin MJ, Allen-Mersh TG (1996) Effect of inferior mesenteric artery ligation on blood flow in the marginal arterydependent sigmoid colon. J Am Coll Surg 183(4):357-360

15. Seike K, Koda K, Saito N et al (2007) Laser Doppler assessment of the influence of division at the root of the inferior mesenteric artery on anastomotic blood flow in rectosigmoid cancer surgery. Int J Colorectal Dis 22(6):689-697

16. Rullier E, Laurent C, Garrelon JL, Michel P, Saric J, Parneix M (1998) Risk factors for anastomotic leakage after resection of rectal cancer. Br J Surg 85(3):355-358 